\title{
Hepatoprotective and Antioxidant Effects of Aqueous Extract of Rauwolfia vomitoria (Apocynaceae) Stem Bark in Wistar Rats
}

\author{
D.B. Youmbie Djanche ${ }^{1, *}$, A. Kada Sanda ${ }^{1}$, D. Fosting ${ }^{1}$, D.S. Essama Mbida ${ }^{2}$ \\ ${ }^{1}$ Department of Biological Sciences, Faculty of Science, University of Bamenda, P.0. Box 39, Bambili, Cameroon. \\ ${ }^{2}$ Department of Animal Biology and Physiology, Faculty of Science, University of Yaounde I, P.0. Box 812, Yaounde, Cameroon.
}

\section{ART IC LE DETAILS}

Article history:

Received 11 March 2021

Accepted 24 March 2021

Available online 02 April 2021

\section{Keywords:}

Antioxidant

Hepatotoxicity

Liver

Rauwolfia vomitoria

\begin{abstract}
A B S T RAC T
Rauwolfia vomitoria is used in Cameroon in indigenous medicine to treat liver diseases. The present study was carried out on the hepatoprotective and antioxidant effects of the plant aqueous extract. Liver toxicity was induced by oral route administration of $\mathrm{CCl}_{4}$ two times per week for four weeks. Rats were given concomitantly by oral route, aqueous extract at the doses of 100,200 and $300 \mathrm{mg} / \mathrm{kg}$ or silymarin four days a week for four weeks. By the end, bloods were collected for liver functional parameters analyses. Liver tissues were removed, to assess to oxidative stress parameters and histological analyses. The extract ( $300 \mathrm{mg} / \mathrm{kg}$ ) decreased enzyme activity of ALT, AST and the level of TG with the percentage $54.23 \%, 49.63 \%$ and $28.74 \%$ respectively while it increased the enzyme activity of SOD, CAT and level of MDA at about $67.16 \%, 71.42 \%$ and $43.80 \%$ respectively compared to control animals. These results suggested that aqueous extract has strong hepatoprotective effect on $\mathrm{CCl}_{4}$-induced liver damage and increase antioxidant defense system activity.
\end{abstract}

\section{Introduction}

The functions of the liver are many and essential for good functioning of body. The dysfunction of liver causes enormous problem of health. Medicinal plants are used to protect liver and treat several hepatitis including, Crassoceplalum crepidioides, Epalttes divaricate and Sarcostemma brevistigma respectively to [1-3]. Rauwolfia vomitoria (Apocynacae) generally known in pharmacopoeia as the mainstay in treatment and preservation of human health [4]. In Cameroon, it is known and referred to as "Nteu ta cheu" in Bangou in West Region, "Chanvengo" in Bamenda in North West Region and "Etoe" in Mfoundi in Centre Region of Cameroon. The plant has different species including Indian species named Rauwolfia serpentine and the African species named Rauwolfia vomitoria ( $R$. vomitoria) [5]. Okpako [6] research showed that, reserpine is a major element of antihypertensive drugs found in Rauwolfia vomitoria in 1952. The children are treated with this plant for cerebral cramps, jaundice and gastrointestinal disorder [7]. In indigenous practice, it is used versus nervous disorders. In Cameroon and Ghana herbalists are used it as an emetic and purgative. In Bangou village-Cameroon, it is used to treat liver diseases. The pharmaceutical derivatives are used mainly as sedative drugs. The sedative property is attributed to its ability to balance body response to stress and anxiety and to increase oxygen delivery to the brain [8]. Constituents like alkaloid, and alstonine, find in the root and leaves of $R$. vomitoria have anticancer properties [9] and antipyretic effect is known [10]. The roots and leaves of the plant are used for treatment cholera and liver diseases [11]. The stem bark of Rauwolfia vomitoria has antiinflammatory and antinociceptive effets and it is non-toxic $[12,13]$. The liver is abdominal organ and the largest one. It is a part of the digestive system [14]. It secretes bile and performs vital function such as purification function, synthesis function, and storage function [14]. It is a gland allowing the synthesis of bile as well as that of several carbohydrates and lipids [14]. It also plays an important role in hemostasis. Although various functions of the liver are carried out by the liver cells or hepatocytes unfortunately liver is also prone to many diseases.

Therefore, this study was undertaken to examine the potential hepatoprotective and antioxidant effects of the aqueous extract of the stem bark of $R$. vomitoria on rats using treated $\mathrm{CCl}_{4}$ hepatotoxicity model.

\section{Experimental Methods}

\subsection{Chemicals and Reagents}

All chemicals and reagents used in this study were of analytical grade. The enzyme kits were obtained from Fortess Diagnostic, United Kingdom and Inmesco, Germany. Absorbances were recorded using Genesys 20 spectrophotometer.

\subsection{Plant Collection and Identification}

Stem bark of Rauwolfia vomitoria was collected in Kepche village, Bangou subdivision of highlands, West region Cameroon $\left(5^{\circ} 14^{\prime} 5^{\prime \prime}\right.$ North and $10^{\circ} 23^{\prime} 57^{\prime \prime}$ East) in August 2019. The plant was identified at the National Herbarium Yaounde, Cameroon by comparison with voucher specimen No.16887/HNC.

\subsection{Preparation of Aqueous Extract of Rauwolfia vomitoria}

The fresh stem bark of plant was cut into pieces, air dried away from solar radiation (temperature between $22-25{ }^{\circ} \mathrm{C}$ ) for two months after which they were pulverized using warm mechanical blender. Two (2) kg of powder obtained was stored in air tight container for further use. Eight hundred (800) g was macerated in 7.5 litters of distilled water for 24 hours and the filtrate obtained was evaporated in an incubator at $45^{\circ} \mathrm{C}$ and 72 . $78 \mathrm{~g}$ of dark brown solid extract was obtained (yield 6.87\%). The plant extract was dissolve in distilled water and administrated by oral route to rats. Basing on a preliminary screening test, carrageenan induced inflammation the doses of 100,200 and $300 \mathrm{mg} / \mathrm{kg}$ body weight were selected.

\subsection{Experimental Animals}

Female Wistar rats weighting 110-130 g were used for all experiments. They were housed in plastic cages $(60 \mathrm{~cm} \times 40 \mathrm{~cm}$ with the high of $30 \mathrm{~cm})$ with natural cycle at ambient temperature $\left(24 \pm 2{ }^{\circ} \mathrm{C}\right)$. The animals were feed with standard food and water ad libitum and fasted for 11 hours with free access to water before hepatotoxicity test.

The animals used in this study were handled, according to ethical guidelines of Cameroon National Veterinary Laboratory as referenced by the approval and heal control No 001/17 CCS/MINEPIA/RD-NW/DDME/SSV. 


\subsubsection{Animal Treatment}

Randomly, rats were separated into eight groups of five as following:

Group I used as control (Control I) and was given distilled water (10 $\mathrm{mL} / \mathrm{kg}$ ). Group II considered as vehicle control and was given olive oil (5 $\mathrm{mL} / \mathrm{kg}$ ). Group III served as pharmacological group and was given aqueous extract at the dose of $300 \mathrm{mg} / \mathrm{kg}$. For in vivo hepatotoxicity induction, rats of groups IV, V, VI, VII and VIII were orally administrated 1 $\mathrm{mL} / \mathrm{kg}$ of $\mathrm{CCl}_{4}\left(1 \mathrm{~mL} / \mathrm{kg}+20 \% \mathrm{CCl}_{4}\right.$ in olive oil $)$ two times per week (Monday and Thursday) for a period of four weeks.

After intoxication of rats by $\mathrm{CCl}_{4}$, group IV served as the $\mathrm{CCl}_{4}$ control (Control II) and was given distilled water. Group V served as the positive control and was orally administrated silymarin $(50 \mathrm{mg} / \mathrm{kg})$ four days a week (Tuesday, Wednesday, Friday and Saturday) for four weeks. Groups VI, VII and VIII were orally administrated aqueous extract of $R$. vomitoria at the doses of 100, 200 and $300 \mathrm{mg} / \mathrm{kg}$ respectively.

At the end of the experiment, animals under ether anaesthesia were sacrificed, on the twenty-ninth day. Blood samples were collected, centrifuged at $3000 \mathrm{rpm}$ for 15 minutes to obtain clear serum. Serum was used for liver functional parameters analysis. The animals were dissected and liver tissues were removed, one part to assess oxidative stress parameters and another part was trimmed down for histological analysis.

\subsection{Biochemical Analysis}

Freshly serum was used for evaluation of hepatic biomarkers. Following the manufacturer protocol, appropriate kits were used for biochemical evaluations. The determinations of the activities of aspartate aminotransferase (AST) and alamine aminotransferase (ALT) and total cholesterol were measured using Inmesco (Germany) kit. The level of alkaline phosphatase (ALP), triglyceride (TG), HDL-cholesterol, LDLcholesterol and total bilirubin (T-BIL) were measured using Fortress diagnostic (United Kingdom) kit. The level of total proteins was estimated using the method described by Gornall et al. [15].

\subsection{Evaluation of Lipid Peroxidation and Antioxidant Biomarkers}

Hepatic tissues collected from each rat were cleaned from any materials and perfused with cold saline. The tissues were homogenised in cold phosphate buffer saline $(0.1 \mathrm{M} \mathrm{pH} 7.4)$. Then, the homogenate was filtered and centrifuged at $3000 \mathrm{rpm}$ for $15 \mathrm{~min}$. The supernatant was used for lipid peroxidation and antioxidant biomarkers as follow: Lipid peroxidation was evaluated colorimetrically by measuring malondialdehyde (MDA) content in the tissues by the method described by Ohkawa $[16,17]$. The procedure to estimate the reduced glutathione (GSH) levels was done according to the method as described by Ellman $[16,18]$. The activity of catalase (CAT) in the tissues was determined by the method of Sinha $[16,19]$. Superoxide dismutase (SOD) activity was measured in supernatant of homogenate by the method of Misra and Fridovich $[16,20]$. The presence of nitrite, a stable oxidized product of Nitric oxide (NO), was determined by the method described by Kim [16,
21]. The protein content in the homogenate was determined by the method of Gornall $[15,16]$.

\subsection{Histopathological Study}

To study the liver sections under microscope, the tissue passed via many proceedings of fixation, dehydration, clearing, infiltration, embedding, sectioning and stain. In fixation, liver samples of all experimental groups were kept in $10 \%$ neutral formalin. After fixation, tissues have been dehydrated in different percentages of alcohol $75 \%$, $95 \%$ and $100 \%$ absolute) embedded in paraffin block and serially sectioned ( $5 \mu \mathrm{m}$ size) using a microtome. Liver sections were stained with mayer hematoxylin and eosin. $\mathrm{CCl}_{4}$ induced liver damage was observe using microscope (Zeiss, Hallbermoos, Germany).

\subsection{Statistical Analysis}

All data were presented as mean \pm E.S.M of five (5) rats. Difference between means was assessed by two ways Analysis of Variance (ANOVA), followed by Bonferroni post-test using Graph pad prism 5.03. Statistical significance was considered at $\mathrm{p}<0.05$.

\section{Results and Discussion}

\subsection{Hepatoprotective Effects of R. vomitoria Aqueous Extract}

Protein content significantly increased $(\mathrm{p}<0.05)$ in control I (normal rats) in tissue and serum when compared to control II (rats treated with $\mathrm{CCl}_{4}$ and distilled water). Oral route administration of the extract at the dose of $300 \mathrm{mg} / \mathrm{kg}$ significantly reduced protein level in tissue and serum by $43.61 \%$ and $47.42 \%$ respectively when compared to control II (Fig. 1).

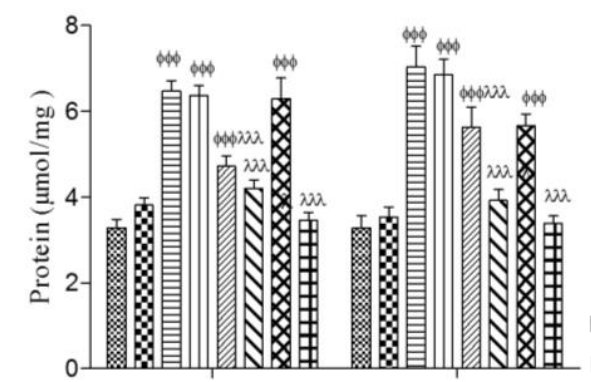

Liver

Serum

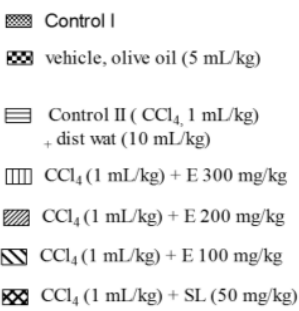

田 Phamacological group (E 300 $\mathrm{mg} / \mathrm{kg}$ )
Fig. 1 Effect of stem bark aqueous extract of $R$. vomitoria on protein in tissue and serum of rat intoxicated by carbon tetrachloride. Each bar is represented as mean \pm S.E.M. $(\mathrm{n}=5) \phi \mathrm{p}<0.05 ; \phi \phi \mathrm{p}<0.01 ; \phi \phi \phi \mathrm{p}<0.001$ : statistically significant compared to Control I (Normal rats). ${ }^{\lambda} \mathrm{p}<0.05 \lambda \mathrm{p}<0.01$ and $\lambda \lambda \lambda_{\mathrm{p}}<0.001$ : statistically significant compared to control II (Intoxicated rats, treated with distilled water). E: Extract; SL: Silymarin; $\mathrm{CCl}_{4}$ : Carbon tetrachloride; dist wat: Distilled water.

Table 1 Effect of stem bark aqueous extract of $R$. vomitoria on AST, ALT, ALP and TBIL in the serum of rats intoxicated by carbon tetrachloride

\begin{tabular}{|c|c|c|c|c|}
\hline Experimental groups & AST (Units/L) & ALT (Units/L) & T BIL (mg/dL) & ALP (Units/L) \\
\hline Control I (distilled water, $10 \mathrm{~mL} / \mathrm{kg}$ ) & $87.95 \pm 4.54$ & $56.54 \pm 6.23$ & $1.11 \pm 0.02$ & $24.03 \pm 1.23^{\kappa \kappa \kappa}$ \\
\hline Vehicle, olive oil ( $5 \mathrm{~mL} / \mathrm{kg})$ & $92.58 \pm 4.90^{\kappa \kappa \Lambda}$ & $61.51 \pm 4.02^{\kappa \kappa \kappa}$ & $1.17 \pm 0.05^{\kappa \kappa \kappa}$ & $22.20 \pm 1.37^{\kappa \kappa \kappa}$ \\
\hline Control II $\left(\mathrm{CCl}_{4} 1 \mathrm{~mL} / \mathrm{kg}\right)+$ distilled water $(10 \mathrm{~mL} / \mathrm{kg})$ & $213.15 \pm 4.54 \kappa \kappa \kappa \phi \phi \phi$ & $155.57 \pm 4.54 \phi \phi \phi$ & $2.01 \pm 0.05 \phi \phi \phi$ & $34.92 \pm 1.45 \phi \phi \phi$ \\
\hline $\mathrm{CCl}_{4}(1 \mathrm{~mL} / \mathrm{kg})+R$. vomitoria $(100 \mathrm{mg} / \mathrm{kg})$ & $202.68 \pm 4.78 \phi \phi \phi$ & $145.10 \pm 4.78 \phi \phi \phi$ & $1.87 \pm 0.02 \phi \phi \phi$ & $31.21 \pm 1.04 \phi \phi$ \\
\hline $\mathrm{CCl}_{4}(1 \mathrm{~mL} / \mathrm{kg})+R$. vomitoria $(200 \mathrm{mg} / \mathrm{kg})$ & $150.07 \pm 5.49 \kappa \kappa \kappa \phi \phi \phi$ & $112.55 \pm 5.21^{\kappa \kappa \kappa \phi \phi \phi}$ & $1.66 \pm 0.02^{\kappa \kappa \kappa \phi \phi \phi}$ & $28.52 \pm 1.54$ \\
\hline $\mathrm{CCl}_{4}(1 \mathrm{~mL} / \mathrm{kg})+R$. vomitoria $(300 \mathrm{mg} / \mathrm{kg})$ & $97.54 \pm 6.75^{\kappa \kappa \kappa}$ & $78.35 \pm 4.06 \kappa \kappa \kappa \phi$ & $1.26 \pm 0.05 \kappa \kappa \kappa \phi$ & $22.95 \pm 1.38 \kappa \kappa \kappa$ \\
\hline $\mathrm{CCl}_{4}(1 \mathrm{~mL} / \mathrm{kg})+\mathrm{SL}(50 \mathrm{mg} / \mathrm{kg})$ & $90.47 \pm 3.71^{\kappa \kappa \kappa}$ & $69.54 \pm 4.75 \kappa \kappa \kappa$ & $1.11 \pm 0.03^{\kappa \kappa \kappa}$ & $24.91 \pm 1.53^{\kappa \kappa \kappa}$ \\
\hline Pharmacological group. $R$. vomitoria (300 mg/kg) & $96.58 \pm 6.15^{\kappa \kappa \kappa}$ & $66.05 \pm 6.07 \kappa \kappa \kappa$ & $1.21 \pm 0.04 \kappa \kappa \AA$ & $24.59 \pm 1.48^{\kappa \kappa \kappa}$ \\
\hline
\end{tabular}

Results are expressed as mean \pm S.E.M; $n=5 . \phi p<0.05, \phi \phi p<0.01$ and $\phi \phi \phi p<0.001$, significantly different compared to Control I (Normal rats); $\lambda p<0.001, \lambda \lambda p<0.01$ and $\lambda \lambda \lambda \lambda<<0.001$ significantly different compared to Control II (Intoxicated rats, treated with distilled water); AST: Aspartate aminotransferase; ALT: Alanine aminotransferase; ALP: Alkaline phosphatase; T BIL: Total bilirubin.

Table 2 Effect of stem bark of aqueous extract of R. vomitoria on total cholesterol, triglyceride, HDL-cholesterol and LDL-cholesterol in the serum of rats intoxicated by carbon tetrachloride

\begin{tabular}{|c|c|c|c|c|}
\hline Experimental groups & Total cholesterol (mg/dL) & Triglyceride (mg/dL) & LDH-cholesterol (mg/dL) & LDL-cholesterol (mg/dL) \\
\hline Control I (distilled water, $10 \mathrm{~mL} / \mathrm{kg}$ ) & $70.68 \pm 1.02$ & $61.02 \pm 1.77$ & $21.12 \pm 0.43$ & $37.35 \pm 1.05$ \\
\hline Vehicle, olive oil ( $5 \mathrm{~mL} / \mathrm{kg})$ & $71.07 \pm 3.02$ & $62.27 \pm 2.68$ & $21.79 \pm 0.63$ & $36.82 \pm 1.98$ \\
\hline Control $\left(\mathrm{CCl}_{4}, 1 \mathrm{~mL} / \mathrm{kg}\right)+$ distilled water $(10 \mathrm{~mL} / \mathrm{kg})$ & $92.07 \pm 1.15$ & $104.24 \pm 1.69 \phi \phi \phi$ & $17.01 \pm 0.15$ & $57.21 \pm 1.82 \phi \phi \phi$ \\
\hline $\mathrm{CCl}_{4}(1 \mathrm{~mL} / \mathrm{kg})+\mathrm{R}$. vomitoria $(100 \mathrm{mg} / \mathrm{kg})$ & $88.05 \pm 2.16 \phi \phi \phi$ & $94.30 \pm 1.28^{\kappa \kappa \phi \phi \phi}$ & $14.15 \pm 0.57$ & $54.71 \pm 1.94 \phi \phi \phi$ \\
\hline $\mathrm{CCl}_{4}(1 \mathrm{~mL} / \mathrm{kg})+\mathrm{R}$. vomitoria $(200 \mathrm{mg} / \mathrm{kg})$ & $81.07 \pm 2.83 \phi \phi$ & $80.53 \pm 2.36^{\wedge \Lambda \phi \phi \phi}$ & $12.56 \pm 0.56 \phi$ & $52.40 \pm 1.99 \phi \phi \phi$ \\
\hline $\mathrm{CCl}_{4}(1 \mathrm{~mL} / \mathrm{kg})+\mathrm{R}$. vomitoria $(300 \mathrm{mg} / \mathrm{kg})$ & $75.57 \pm 2.67 \phi$ & $76.42 \pm 3.48^{\kappa \kappa \varnothing \phi \phi \phi}$ & $17.62 \pm 0.62$ & $42.66 \pm 1.64 \kappa \kappa \kappa$ \\
\hline $\mathrm{CCl}_{4}(1 \mathrm{~mL} / \mathrm{kg})+\mathrm{SL}(50 \mathrm{mg} / \mathrm{kg})$ & $78.05 \pm 2.47 \kappa \kappa \kappa \phi \phi$ & $79.31 \pm 2.57 \kappa \kappa \kappa \phi \phi \phi$ & $16.55 \pm 1.13$ & $42.64 \pm 1.39 \kappa \phi \phi$ \\
\hline Pharmacological group, $R$. vomitoria (300 mg/kg) & $67.15 \pm 1.81^{\kappa \kappa \kappa}$ & $58.69 \pm 3.23^{\kappa}$ & $23.60 \pm 0.53$ & $31.81 \pm 1.07 \kappa \kappa \kappa$ \\
\hline
\end{tabular}

Results are expressed as mean \pm S.E.M; $n=5 .{ }^{\phi} p<0.05, \phi \phi p<0.01$ and $\phi \phi \phi p<0.001$ significantly different compared to Control I (Normal rats). ${ }^{\prime} p<0.05,{ }^{\wedge} p<0.01$ and ${ }^{\lambda \kappa} p<0.001$ significantly different compared to Control II (Intoxicated rats, treated with distilled water). 
Table 3 Effect of stem bark of aqueous extract of $R$. vomitoria on reduced GSH, MDA, SOD, CAT and nitrite in the tissue of rats intoxicated by carbon tetrachloride

\begin{tabular}{|c|c|c|c|c|c|}
\hline Experimental groups & $\begin{array}{l}\mathrm{GSH}(\mu \mathrm{mol} / \mathrm{mg} \\
\text { protein) }\end{array}$ & $\begin{array}{l}\text { MDA }(\mu \mathrm{mol} / \mathrm{mg} \\
\text { protein })\end{array}$ & $\begin{array}{l}\text { SOD }(\mu \mathrm{mol} / \mathrm{mg} \\
\text { protein })\end{array}$ & $\begin{array}{l}\text { CAT }\left(\mu \text { mol of } \mathrm{H}_{2} \mathrm{O}_{2} \text { broken up }\right. \\
/ \mathrm{mn} / \mathrm{mg} \text { protein })\end{array}$ & $\begin{array}{l}\text { Nitrite }(\mu \mathrm{mol} / \mathrm{mg} \\
\text { protein) }\end{array}$ \\
\hline Control I (distilled water, $10 \mathrm{~mL} / \mathrm{kg}$ ) & $8.94 \pm 0.51$ & $1.15 \pm 0.03$ & $7.43 \pm 0.43$ & $3.68 \pm 0.05$ & $0.12 \pm 0.02^{\kappa}$ \\
\hline Vehicle, olive oil (5 mL/kg) & $8.82 \pm 0.44 \kappa \kappa \kappa$ & $1.20 \pm 0.04 \kappa \kappa \kappa$ & $7.40 \pm 0.66^{\kappa \kappa \kappa}$ & $3.53 \pm 0.0^{\kappa \kappa \Lambda}$ & $0.13 \pm 0.02^{\kappa}$ \\
\hline Control II $\left(\mathrm{CCl}_{4}, 1 \mathrm{~mL} / \mathrm{kg}\right)+$ distilled water $(10 \mathrm{~mL} / \mathrm{kg})$ & $3.29 \pm 0.36 \phi \phi \phi$ & $2.38 \pm 0.05 \phi \phi \phi$ & $3.09 \pm 0.45 \phi \phi \phi$ & $1.62 \pm 0.03 \phi \phi \phi$ & $0.20 \pm 0.01 \phi$ \\
\hline $\mathrm{CCl}_{4}(1 \mathrm{~mL} / \mathrm{kg})+R$. vomitora $(100 \mathrm{mg} / \mathrm{kg})$ & $4.35 \pm 0.43 \phi \phi \phi$ & $2.18 \pm 0.03 \phi \phi \phi$ & $4.54 \pm 0.30^{\kappa \phi \phi \phi}$ & $2.07 \pm 0.05^{\kappa \kappa \kappa \phi \phi \phi}$ & $0.18 \pm 0.02$ \\
\hline $\mathrm{CCl}_{4}(1 \mathrm{~mL} / \mathrm{kg})+R$. vomitora $(200 \mathrm{mg} / \mathrm{kg})$ & $6.09 \pm 0.40^{\kappa \phi \phi \phi}$ & $1.75 \pm 0.03^{\kappa \kappa \kappa \phi \phi \phi}$ & $4.55 \pm 0.23^{\kappa \phi \phi \phi}$ & $2.52 \pm 0.04 \kappa \kappa \kappa \phi \phi \phi$ & $0.16 \pm 0.02$ \\
\hline $\mathrm{CCl}_{4}(1 \mathrm{~mL} / \mathrm{kg})+R$. vomitora $(300 \mathrm{mg} / \mathrm{kg})$ & $8.00 \pm 0.30^{\kappa \kappa \kappa}$ & $1.34 \pm 0.05^{\kappa \kappa \kappa \phi}$ & $5.16 \pm 0.26^{\kappa \kappa \phi \phi}$ & $3.10 \pm 0.03 \kappa \kappa \kappa \phi \phi \phi$ & $0.11 \pm 0.01^{\kappa \kappa}$ \\
\hline $\mathrm{CCl}_{4}(1 \mathrm{~mL} / \mathrm{kg})+\mathrm{SL}(50 \mathrm{mg} / \mathrm{kg})$ & $8.52 \pm 0.44^{\kappa \kappa \kappa}$ & $1.20 \pm 0.02^{\kappa \kappa \kappa}$ & $6.82 \pm 0.29^{\kappa \kappa \kappa}$ & $3.22 \pm 0.04 \kappa \kappa \kappa \phi \phi \phi$ & $0.11 \pm 0.01^{\kappa \kappa}$ \\
\hline Pharmacological group. $R$. vomitora (300 mg/kg) & $8.48 \pm 0.32^{\kappa \kappa \kappa}$ & $1.23 \pm 0.04 \kappa \kappa \kappa$ & $6.80 \pm 0.35^{\kappa \kappa \kappa}$ & $3.60 \pm 0.03^{\kappa \kappa \Lambda}$ & $0.12 \pm 0.02^{\kappa \kappa}$ \\
\hline
\end{tabular}

Results are expressed as mean \pm S.E.M; $n=5 . \phi p<0.05, \phi \phi p<0.01$ and $\phi \phi \phi p<0.001$ significantly different compared to Control I (Normal rats). ${ }^{K} p<0.05$, « $p<0.01$ and $\lambda \ll i n<0.001$ significantly different compared to Control II (Intoxicated rats, treated with dilled water). CCl4: Carbon tetrachloride; SL: Silymarin; GSH: Reduced glutathione; MDA: Malondialdehyde; SOD: Superoxyde dismutase; CAT: Catalase.
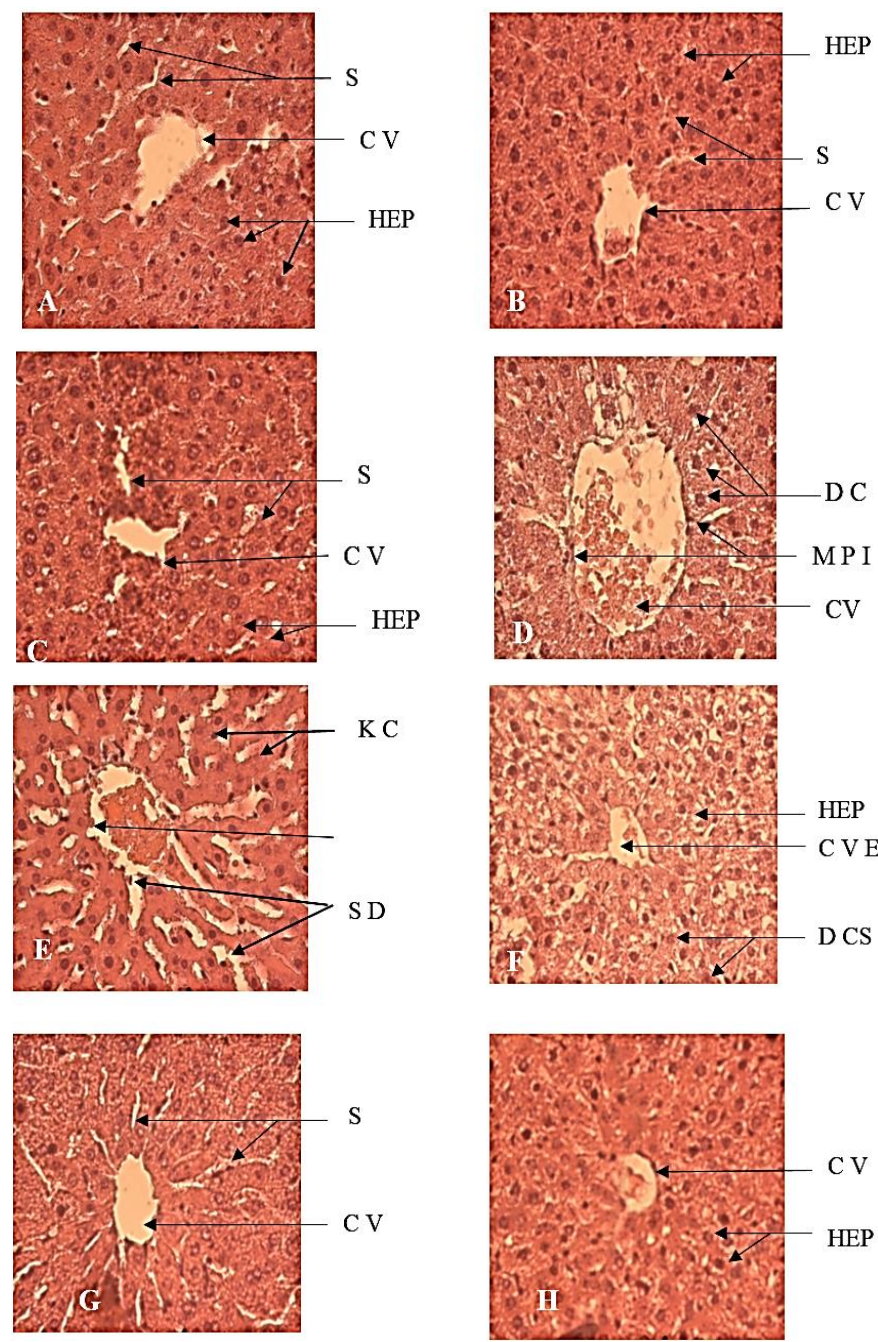

Fig. 2 Microphotographs of liver structure to observe the effects of aqueous extract of $R$. vomitoria in intoxicated rats by carbone tetrachloride and morphological analysis. Stained hematoxylin eosin. Magnification: $(\times 400)$. Control I or Normal rats (Fig. 2A); vehicle, olive oil $5 \mathrm{mg} / \mathrm{Kg}$ (Fig. 2B); Pharmacological group (Fig. 2C); Control II or intoxicated rats treated with distilled water (Fig. 2D); $\mathrm{CCl}_{4}+$ aqueous extract (100 mg/kg) (Fig. 2E); $\mathrm{CCl}_{4}+$ aqueous extract (200 mg/kg) (Fig. 2F); $\mathrm{CCl}_{4}+$ aqueous extract (300 mg/kg) (Fig. 2G); $\mathrm{CCl}_{4}+$ silymarin (50 mg/kg) (Fig. $2 \mathrm{H}$ ). $\mathrm{CCl}_{4}$ : Carbon tetrachloride; CV: Central vein; HEP: Hepatocytes; S: Sinusoids; DC: Degenerating cells; MPI: Mild portal inflammation; KC : Kupffer cells; CVE: Central vein enlargement; SD: Sinusoid dilatation.

Activities of AST, ALT, ALP, as well as total bilirubin level were markedly elevated in control II (rats treated with $\mathrm{CCl}_{4}$ and distilled water) when compared to control I (normal rats), indicating liver injury. Whereas, rats of pharmacological group or vehicle did not show significant different compared to control I. However, administration of aqueous extract significantly lowered $(\mathrm{P}<0.001)$ the elevation of serum enzymes and total bilirubin. Furthermore, treatment with the aqueous extract at the dose of $300 \mathrm{mg} / \mathrm{kg}$ significantly decreased the percentages of AST, ALT, ALP and total bilirubin by $54.43 \%, 49.63 \%, 34.27 \%$ and $37.27 \%$ respectively, compared to control II (Table 1). Control II showed significant increase ( $\mathrm{p}<0.001)$ of total cholesterol, triglyceride and LDL-cholesterol $(30.27 \%$, $70.80 \%$ and $45.15 \%$ respectively) when compared to control I. The administration of Rauwolfia vomitoria aqueous extract at the dose of 300 https://doi.org/10.30799/jpmr.053.21060101 $\mathrm{mg} / \mathrm{kg}$ significantly reduced activities of total cholesterol, triglyceride and LDL-cholesterol $(17.96 \%, 26.68 \%$ and $21.31 \%$ respectively) compared to control II. Whereas, rats of pharmacological group and vehicle control did not show significant change in serum lipid parameters compared to control I. Silymarin, drug reference also reduced significantly $(p<0.001)$ the activities of serum lipid parameters (Table 3).

\subsection{Antioxidant Effects of Aqueous Extract of R. vomitoria}

MDA levels in control II or rats treated with $\mathrm{CCl}_{4}$ and distilled water $(2.38 \pm 0.02 \mu \mathrm{mol} / \mathrm{mg}$ protein) were significantly higher than in control I or normal rats $(1.15 \pm 0.03 \mu \mathrm{mol} / \mathrm{mg}$ protein; $\mathrm{p}<0.001)$. Furthermore, nitrite levels in control II $(0.20 \pm 0.01 \mu \mathrm{mol} / \mathrm{mg}$ protein) were also higher than in control I $(0.12 \pm 0.02 \mu \mathrm{mol} / \mathrm{mg}$ protein; $\mathrm{p}<0.05)$. Administration of the aqueous extract decreased significantly $\mathrm{CCl}_{4}$ induced hepatic peroxidation. MDA and nitrite levels significantly reduced by $43.80 \%$ and $44.54 \%$ respectively in the group that received the aqueous extract at the dose of $300 \mathrm{mg} / \mathrm{kg}$ compared to control II $(\mathrm{p}<0.05)$. Silymarin also prevented the elevation of MDA ant nitrite levels after administration of $\mathrm{CCl}_{4}$ (Table 3). In control II, $\mathrm{CCl}_{4}$ significantly $(\mathrm{p}<0.01)$ decreased the reduced GSH level in liver as compared to control I. In contrast, rat treated with aqueous extract at doses of 200 and $300 \mathrm{mg} / \mathrm{kg}$ showed significantly increased reduced GSH levels by $43.42 \%$ and $45.26 \%$ respectively compared to control II. Similar results were also found with the dose of 50 $\mathrm{mg} / \mathrm{kg}$ of silymarin (Table 3 ). Significant decreasing $(\mathrm{p}<0.01)$ of the activities of SOD and CAT were observed in control II as compared to control I. There were significant increases in SOD and CAT activities in the aqueous extract treated groups compared to control II. The group treated with the aqueous extract of $R$. vomitoria at the dose of $300 \mathrm{mg} / \mathrm{kg}$ showed a significantly increased of the activity of SOD ( $<<0.05$ by $20.00 \%)$ and CAT ( $\mathrm{p}<0.05$ by $24.30 \%$ ) when compared to control II (Table3).

The liver toxicity induced by carbon tetrachloride $\left(\mathrm{CCl}_{4}\right)$ in many experimental studies causes systemic effects throughout the body. This inducing agent causes oxidative stress and damage to several organs including the liver [22], kidney [23] and spleen [24]. It was also established that, $\mathrm{CCl}_{4}$ could induce the activation of inducible NO synthase for the production of nitric oxide [25]. Nitrite is a stable product of NO, and NO is an inflammation mediator that induces the synthesis of prostaglandins, cytokines and reactive oxygen species (ROS) which justify the systemic effects.

Administration of $\mathrm{CCl}_{4}$ has caused a significant decrease the reduced glutathione (GSH), and catalase (CAT) and superoxide dismutase (SOD) activities in control II (rats treated with $\mathrm{CCl}_{4}$ and distilled water) compared to control I (normal rats). CAT and SOD are enzymes that protect body against free radicals. They are mediated by superoxide anion $\left(\mathrm{O}_{2}^{-}\right)$and hydrogen peroxide $\left(\mathrm{H}_{2} \mathrm{O}_{2}\right)$ [26]. The decrease in CAT and SOD in animals treated with $\mathrm{CCl}_{4}$ in this study would be due to membrane damage and impaired dynamic permeability of membranes caused by lipid peroxidation. This lipid peroxidation was confirmed in this study by increasing in the level of Malondialdehyde (MDA) in control II compared to control I. The aqueous extract has significantly increased the levels of GSH, CAT and SOD activities compared to control II. This ability of the extract to restore the level of GSH and the activities of enzymes (CAT and SOD) would be due to the ability of the bioactive metabolites contained in the extract to inhibit the synthesis of NO and to limit the synthesis of ROS to reduce oxidative stress and pro inflammatory mediators. The administration of $\mathrm{CCl}_{4}$ has caused a significant increasing of the level of MDA, nitrites and serum proteins in control II compared to control I. The aqueous extract significantly decreased the levels of MDA, protein and nitrite in this model of liver toxicity. The decreasing in MDA level could result from an inhibitory action of lipid peroxidation by the metabolites contained in our plant extract. Phytochemical analysis revealed that the extract contains tannins, terpenoids, triterpenes and vitamin C. The work of Padatty et al. [27] has shown that vitamin C is an antioxidant substance 
which directly or indirectly lowers lipid peroxidation by regeneration of vitamins E. Vitamin C could scavenge free radicals from Reactive Oxygen Species (ROS) by fast transfer of electrons during the inhibition of lipid peroxidation [28] to act indirectly as an antioxidant. In the present study, histological observations (Fig. 2) have shown that, oral administration of $\mathrm{CCl}_{4}$ induced hepatocyte degeneration of control II when compared to control I.

These results indicate that during intoxication $\mathrm{CCl}_{4}$ could cause hepatocyte destruction [29] which could explain liver abnormalities observed in this study. At a dose of $300 \mathrm{mg} / \mathrm{kg}$, the aqueous extract repairs damaged hepatocytes, suggesting that the extract would contain substances capable to regenerate hepatocytes.

Administration of $\mathrm{CCl}_{4}$ has caused a significant increase of aspartate amino transferase (ASAT), alanine amino transferase (ALAT), bilirubin and alkaline phosphatase (PAL) in control II (rats treated with $\mathrm{CCl}_{4}$ and distilled water compared to control I (normal rats). It is known that $\mathrm{CCl}_{4}$ activates peroxidase and phosphatase which lead to oxidation of hepatocyte membrane, inducing an increase of the levels of ALT, ASAT, PAL and bilirubin [25]. The activation of cholestasis by $\mathrm{CCl}_{4}$ blocks the bile ducts to provoke hyperbilirubinemia and hypercholesterolemia [30] and therefore increase ALT, ASAT, PAL and bilirubin. When liver cell plasma membrane is damaged, a variety of enzymes normally located in the cytosol are released into the blood stream with higher concentration in serum. Therefore, measurements of the activities of serum marker like ALAT, ASAT have provided a powerful tool for the assessment of liver function [31].

Administration of the aqueous extract has improved the levels of ASAT, ALAT, bilirubin and PAL, suggesting that the extract would contain substances capable to inhibit peroxidase, phosphatase and cholestasis. The flavonoids present in the extract [12] may also explain the improvement observed in liver function. Indeed, the flavonoids could directly protect the mitochondria, by inhibiting the cytochromes P 450 $2 \mathrm{E} 1$ which are the main responsible for the bioactivation of $\mathrm{CCl}_{4}$ [32]. Our results indicate that $\mathrm{CCl}_{4}$ administered at a dose of $1 \mathrm{~mL} / \mathrm{kg}$ has caused a significant increase of total cholesterol, triglycerides and LDL-cholesterol of control II (rats treated with distilled water) compared to control I (Normal rats). Hypercholesterolemia and hypertriglyceridemia are independent risk factors that alone or together could accelerate the development of coronary heart disease and the progression of atherosclerotic lesions [33]. Indeed, $\mathrm{CCl}_{4}$ reduces the activity of the enzymes lipoprotein lipase and triglyceride lipase and decreases the oxidation of fats, thus provoking the accumulation of triglycerides in the serum and increases the bioavailability of free fatty acids (glycerophosphates) [33].

The increasing of total cholesterol level is due to an increasing of the activity of enzyme $\beta$-hydroxymethylglutaryl CoA (HMGCoA), which leads to an increase in the synthesis of cholesterol and its release in the blood stream [33]. Administration of the aqueous extract of $R$. vomitoria improved the lipid profile of the animals. These results suggest that the extract contains bioactive compounds with lipid-lowering properties. These bioactive compounds could inhibit the intestinal absorption of dietary cholesterol or the synthesis of cholesterol by the liver and stimulate the biliary secretion of cholesterol and then its excretion in the poo to reduce the level of total cholesterol [34]. The lipid-lowering properties of the extract could also be due to the inhibition exerted by bioactive components such as tannins [12] on the activity of certain enzymes, in particular lipoprotein lipase, triglyceride lipase and/or $\beta$ hydroxymethylglutaryl CoA [27].

Analyses of histological sections of the liver of rats treated with $\mathrm{CCl}_{4}$ and with the extract at doses of 100 and $200 \mathrm{mg} / \mathrm{kg}$ indicate architectural modifications of the liver causing infiltration of inflammatory cells, dilation of sinusoid capillaries and the presence of Kupfer cells compared to control I. The work of Brattin et al. [35] showed that the metabolic biotransformation of $\mathrm{CCl}_{4}$ into trichlomethyl $\left(\mathrm{CCl}_{3}\right)$ by covalent bond binds to the $\mathrm{OH}$ group of membrane phospholipids of hepatocytes induces cell destruction and an increasing of transaminases. The metabolic biotransformation of $\mathrm{CCl}_{4}$ to dioxytrichlomethyl $\left(\mathrm{CCl}_{3} \mathrm{O}_{2}\right)$ causes cellular abnormalities such as DNA damage, necrosis, hepatocyte degeneration and liver fibrosis [36].

Administration of the extract $\left(300 \mathrm{mg} / \mathrm{kg}\right.$ ) to rats receiving $\mathrm{CCl}_{4}$ has improved these structural alterations, suggesting that the extract would contain substances capable to protect cell membranes, reducing the toxic effects of $\mathrm{CCl}_{4}$, regenerating and / or repairing destroyed hepatocytes. These results can be explained by accepting like Monday et al. [37] who worked with the ethanolic extract of the roots of $R$. vomitoria combined with vitamin $\mathrm{E}$, that $R$. vomitotia would protect the liver against destructive enzymes. The phytoconstituents, namely polyphenols, alkaloids and vitamin C identified $[12,16]$ in this extract which have contributed to repair and/or regenerate hepatocytes destroyed by $\mathrm{CCl}_{4}$.

\section{Conclusion}

The findings of the present investigation prove that aqueous extract of Rauwolfia vomitoria stem bark was efficient for the treatment of $\mathrm{CCl}_{4-}$ induced hepatic damage in rats. The results exhibit that hepatoprotective effect of aqueous extract, probably due to both an increasing in the activity of the antioxidant-defense system and an inhibition of lipid peroxidation.

\section{Acknowledgements}

This research was partially funded by Pr. Maurice Aurélien SOSSO, Rector of the University of Yaounde 1-Cameroon for encouragement Indeed, the authors wish to thank him for valuable financial assistance. The authors wish to thank also Mr. Takala Jean Claude, technician laboratory in faculty of medicine and biomedical science of University of Yaoundé 1 for his implication in histological realisation. The authors wish to thank also Dr. Keugni Brice Armand for his support to structure this manuscript.

\section{References}

[1] Y. Aniya, T. Koyama, M. Miyagi, C. Inomata, S. Kinoshita, T. Ichaba, Free radical scavenging and hepatoprotective actions of medicinal herb, Crassocephalum crepiddioides from the Okinawa Islands, Biol. Pharm. Bull. 28 (2005) 19-23.

[2] R.P. Hewawasam, K.A.P.W. Jayatilaka, C. Pathirana, L.K.B. Mudduwa, Hepatoprotective effect of Epaltes divaricate extract on carbon tetrachloride induced hepatotoxicity in mice, Indian J. Med. Res. 120 (2004) 30-34.

[3] M.G. Sethuraman, H.G. Lalitha, B. Rajkapoor, Hepatoprotective activity of Sarcostemma brevistigma against carbon tetrachloride induced hepatic damage in rats, Curr. Sci. 84(9) (2003) 1186-1187.

[4] L.S. Gill, Ethnomedical uses of plants in Nigeria, Uniben Press, University of Benin Press, Negeria, Benin, 1992.

[5] R. Kutalek, A. Prinz, African medicinal plants, In: Yaniv Z and U. Bachrach (Eds.), Handbook of medicinal plants, New Delhi, CBS Publishers, 2007.

[6] D.T. Okpako, Principal of pharmacology: A tropica Aproach, New York, Cambridge University Press, 1991.

[7] Y. Zohera, B. Uriel, Handbook of medicinal plants, Haworth Press, New York, USA, 2005.

[8] B. Oliver, Medicinal plants in Tropical West Africa plant acting on cardiovascular system, J. Ethnopharmacol. 5 (1982) 1-17.

[9] D.L. Denis, J.L. Capodice, A.E. Katz, R. Buttyan, Antiprostrate cancer activity of a carboline alkaloid enriched extract from Rauwolfia vomitoria, Int. J. Oncol. 5 (2006) 1065-1073.

[10] 0.O. Amol, A.O. Onabanjo, Antipyretic effects of the extract of Rauwolfia vomitoria in rabbits, Nig. J. Nat Prod. And Med. 3 (1991) 77-78.

[11] Z. Shavorov, The healing powers of parasympathetic pathways, J. Clin. Invest. 10 (1965) 2613-2620.

[12] D.D.B. Youmbie, D.P.D. Dzeufiet, E. Nkwengoua, C. Mezui, T. Dimo, Antiinflammatory and antinociceptive effets of the stem bark aqueous extract of Rauwolfia vomitoria, J. Pham. Pharm. Sci. 7 (2015) 90-112.

[13] D.D.B. Youmbie, D.P.D. Dzeufiet, S.A. Kada, D. Fotsing, T. Dimo, Acute and subacute toxicity of the stem bark aqueous extract of Rauwolfia vomitoria, W. J. Adv. Res. Rev. 3 (2020) 373-385.

[14] B.S.F. Singhkaram, B. Yerma, Hepatoprotection through Ayurvedic Herbs, Int. J. Ayu. Herb. Med. 5 (2012) 885-896.

[15] A.G. Gornal, G.S. Bardawil, M.M. David, Determination of serum proteins by the mean of the buiret reactions, J. Biol. Chem. 177 (1949) 751-766.

[16] D.D.B. Youmbie, D.P.D. Dzeufiet, E. Nkwengoua, S. Zingue, C. Mezui, T. Dimo, Anti-inflammatory and antioxidant effects of the stem bark aqueous extract of Rauwolfia vomitoria in female wistar rats, Eur. J. Pham. Med. Res. 7 (2015) 6473.

[17] H. Ohkawa, N. Ohishi, K. Yagi, Assay for lipid peroxides in animal tissue by thiobarbituric acid reaction, An. Biochem. 95 (1979) 351-358.

[18] G.L. Ellman, Tissue sulfhydrl groups, Arch. Biochem. Biophys. 82 (1959) 70-77.

[19] A.K. Sinha, Colorimetric essay of catalase, Anal. Biochem. 47 (1972) 389-394.

[20] H.P. Misra, I. Fridovic, The role of superoxide anion in the autoxidation of epinephrine and a sample assay for superoxide dismutase, J. Biol. Chem. 247 (1993) 170-174

[21] K.M. Kim, S.B. Chum, M.S. Koo, W.J. Choi, Y.G. Kwon, H.T. Chung, Differential regulation of $\mathrm{NO}$ availability from macrophages and endothelial cells by the garlic component S-allyl cysteine free radicals, J. Biol. Med. 7 (2001) 747-756.

[22] M. Rasool, E.P. Sabina, Anti-inflammatory effect of the Indian ayurvedic herbal formulation triphala on adjuvant-induced arthritis in mice, J. Phyt. Res. 21 (2007) 889-894.

[23] E.M. Conner, M.B. Grisham, Inflammation free radicals and antioxidant, Nutrition. 2 (1996) 274-277.

[24] R.O. Recknalgel, J.R. Glende, J.A. Dolak, R.L. Waller, Mechanisms of carbon tetrachloride toxicity, J. Pharm. Ther. 43 (1989) 139-154.

[25] G.S. Reynolds, G.J. Tortora, Principles of anatomy and Physiology, $8^{\text {th }}$ Edn. Happer Collins College Publisher, New York, USA, 1996.

[26] A. Pichard, Carbon tetrachloride, Edition Masson, Paris, 2005.

[27] S.Y. Padayatty, A. Katz, Y. Wang, P. Eck, O. Kwon, J.H. Lee, Vitamin C as antioxidant: Evaluation of its role in disease prevention, J. Am. Col. Nutr. 22(1) (2003) 18-35. 
[28] B. Frei, L. England, B.N. Ames, Ascorbate is an outstanding in human blood plasma, J. Acad. Sci. 16 (1989) 6377-6381.

[29] R.O. Recknalgel, J.R. Glende, J.A. Dolak, R.L. Waller, Mechanisms of carbon tetrachloride toxicity, J. Pharm. Ther. 43 (1989) 139-154.

[30] G. Agbor, J. Oben, B. Nkegoum, J.P. Takala, J. Ngogang, Hepatoprotective activity of Hibiscus cannabinus Linn against carbon tetrachloride and paracetamol induced liver damage in rat, Pak. J. Biol. Sci. 10 (2005) 1397-1401.

[31] D.S.M. Essama, G.I.N. Otto, G.E. Enow, P. Amang, P.V. Tan, Acute and subacute toxicological study of the aqueous extract of stem bark of Khaya grandifolia in Wistarrats, J. Pharm. Med. Res. 5(1) (2020) 106-111.

[32] F.W.Y. Wong, W.Y. Chan, S.S.T. Lee, Resistance to carbon tetrachloride-induced hepatotoxicity in mice which lack CYP2E1 expression, Toxicol. Appl. Pharmacol. 153 (1998) 109-118.
[33] M. Umamaheswari, T.K. Chatterjee, Effect of the fractions of Ciccinia grandis on ethanol induced cerebral oxidative stress in rats, Phcog. Res. 1 (2009) 25-34.

[34] R. Krzeminski, S. Gorinstein, H. Leontowicz, M. Leontowicz, M. Gralak, J. Czerwinski, Effect of different olive oils on bile excretion in rats fed cholesterolcontaining and cholesterol-free diets, J. Agric. Food Chem. 51 (2003) 57745779 .

[35] W.J. Brattin, J.R. Glende, R.O. Recknagel, Pathological mechanisms in tetrachloride hepatotoxicity, J. Free Radic. Biol. Med. 1 (1985) 27-38.

[36] S. Basu, Carbon tetrachloride-induced lipid peroxidation: eicosanoid formation and their regulation by anti-oxidant nutrients, Toxicology 89 (2003) 113-127.

[37] I.A. Monday, E.U. Friday, B.E. Theresa, B.U. Imeh, U.E. Eyong, O.U. Sylvanus, The effect of interaction of Rauwolfia vomitoria with vitamin E on rats' liver enzymes, Niger. J. Health Biomed. Sci. 33 (2008) 110-120. 